\title{
Inovação aberta: estratégia propulsora de valor em empresas de base tecnológica
}

\section{Open Innovation: propelling strategy for value in technology based companies}

\author{
Renata de Souza França Doutoranda em Sistemas de Informação e Gestão do Conhecimento, Universidade Fumec. Professora \\ Universidade do Estado de Minas Gerais (UEMG), Brasil - profrenatafranca@gmail.com. \\ Fábio Correa Doutor em Sistemas de Informação e Gestão do Conhecimento. Professor Faculdade Newton Paiva \\ (FNP), Brasil - fabiocontact@gmail.com. \\ Eric de Paula Ferreira Doutorando em Sistemas de Informação e Gestão do Conhecimento, Universidade Fumec, Brasil - \\ eric.p.f@gmail.com. \\ Fabrício Ziviani Doutor em Ciência da Informação, Universidade Fumec (FUMEC), Professor Universidade do Estado de \\ Minas Gerais (UEMG) e Fundação Dom Cabral (FDC). contato@fabricioziviani.com.br.
}

\section{RESUMO}

A inovação torna-se ferramenta para geração de ideias, desenvolvimento do capital intelectual e utilização eficiente de recursos. Entretanto, a realidade é a ausência de recursos que viabilizam o processo de inovação. A inovação aberta é uma proposta para criação de valor organizacional, em que as empresas se apoiam. $O$ objetivo desse estudo é determinar quais os fatores advindos da inovação aberta influenciam as Empresas de Base Tecnológica para a criação de valor. Realizou-se uma pesquisa quantitativa e descritiva, com questionário do tipo survey, a colaboradores de Empresas de Base Tecnológica brasileiras. Os resultados apontaram que as redes de conhecimento e o perfil de inovação são necessários para a definição das práticas de inovação aberta e, os fatores de inovação aberta: estabelecimento de parcerias, desenvolvimento de produtos por licenciamento e patentes, spin in e spin off, corporate venturing e cadeia de valor influenciam significativamente a criação de valor organizacional.

Palavras-chave: Valor. Perfil Inovador. Redes. Conhecimento. Inovação Aberta.

\section{ABSTRACT}

Innovation is considered a tool that stimulates the generation of ideas, the development intellectual capital and efficient utilization of resources. However, in reality, there are no resources available to enable the process of innovation. Open innovation is a proposal to create organizational value and allow companies to support each other. The objective of this study is to determine which factors originated from open innovation influence the creation of value in technology based companies. It is a quantitative and descriptive research that made use of a survey applied to employees of a technology based company. The results showed that knowledge network and the innovation profile are aspects necessary for the definition practices of open innovation and the open innovation factors: establishing partnerships, development of products through licenses and patents, spin in and spin off, Corporate Venturing and value chain, influence the creation of organizational values.

Keywords: Value. Innovative profile. Knowledge, Network. Open Innovation. 


\section{INTRODUÇÃO}

A partir da Revolução Industrial, as empresas passaram a atuar em escala global e aumentaram seus volumes de produção consideravelmente em busca de vantagens econômicas e proteção de investimentos e recursos. Com o avanço tecnológico, as perspectivas empresariais foram modificadas e as gestões verticalizadas abriram espaço para as arquiteturas organizacionais modulares e flexíveis (CHESBROUGH, 2006; PITASSI, 2012). Nesse contexto, o conhecimento torna-se o elemento extrema importância para as organizações e passa a ser visto como ferramenta estratégica para a busca de valor organizacional (ZIVIANI et al. 2016).

A exigência de capacidades para o desenvolvimento de produtos, serviços e negócios que atendam ao mercado faz com que a utilização das tecnologias seja aliada ao planejamento estratégico das organizações e abre espaço para as Empresas de Base Tecnológica (CHANDRA; CHAO, 2011;BOCKEN, 2015). Segundo Santos e Pinho (2010, p. 1), as Empresas de Base Tecnológica (EBT) "são firmas cuja intensa dinâmica inovativa se sustenta em sólidas competências técnicas, havendo em relação a elas uma expectativa de crescimento acelerado".

As Empresas de Base Tecnológica mantiveram controle sobre a própria capacidade interna de desenvolvimento e inovação, mantendo sigilo de suas informações e recursos. No entanto, manter uma equipe de desenvolvimento altamente qualificada e um centro de Pesquisas e Desenvolvimento interno pode ser oneroso e inviável, haja vista a falta de capital intelectual suficiente, na disponibilidade reduzida de recursos e na redução de orçamento para inovação (STAL; NOHARA; CHAGAS JUNIOR, 2014; JOHANNSON et al., 2015).

$O$ desenvolvimento de parcerias entre as organizações surge como uma oportunidade estratégica a ser utilizada, dando vistas a um novo tipo de inovação, que permite a criação de competências e valores que não seriam construídos isoladamente. Reconhece-se que fornecedores, consumidores, centros de pesquisa e até mesmo os concorrentes são fontes de ideias com capacidade para apoiar o crescimento organizacional (VECCHIATO, 2015; HERRERA, 2015). A inovação aberta cria um caminho de mão dupla em que o conhecimento e os recursos tramitam de forma contínua, suprindo os déficits existentes nas organizações parceiras (LIU; ZHENG, 2011; CHEN, 2014).

Nesse cenário, onde as Empresas de Base Tecnológica inovam com ideias e recursos de outras empresas, dentro da própria perspectiva organizacional, respeitando os valores e as características de mercado, Lindegaard (2010) e Saebi e Foss (2015) enfatizam que, estratégias bem definidas e alinhadas aos conceitos de inovação aberta, proporcionam que os objetivos organizacionais sejam alcançados. Assim, tornase necessária a criação de um ambiente propicio à inovação e uma cultura que seja capaz de estimulá-la (DIAS, 2013; COSTA, 2014), identificando os fatores de influência da inovação aberta nas empresas como oportunidade de crescimento organizacional.

Diante desse cenário, o estudo tem por objetivo determinar quais os fatores advindos da inovação aberta podem influenciar as Empresas de Base Tecnológica para a criação de valor. Para tratar essa perspectiva, são elaboradas quatro seções. A primeira apresenta uma exposição introdutória. A segunda seção apresenta os principais conceitos que embasaram a análise e discussão dos resultados, seguida da elucidação dos procedimentos metodológicos utilizados (seção 4) e a quarta seção expõe os resultados, sendo sucedido pelas considerações finais. Findando o estudo, posteriormente são apresentadas as referências utilizadas para completude desse estudo.

\section{O PARADIGMA DA INOVAÇÃO ABERTA E SUAS PREMISSAS}

A realidade de muitas organizações no mercado atual se exime a falta de recursos e investimentos, que tornam complexo seu desenvolvimento. Organizações consideradas líderes de mercado enfrentam dificuldades para sustentarem investimentos internos e manterem a busca por capital humano capacitado e criativo, que auxiliem na criação de valor organizacional (CHESBROUGH, 2003; FLORES et al., 2015).

Todavia, manter o conhecimento dentro das organizações é algo oneroso e de grande complexidade, exigindo que os processos organizacionais não se limitem ao know-howinterno de uma organização. Abre-se 
um caminho que vise democratizar a inovação e direcionar as organizações às fontes de conhecimento externo: a Inovação Aberta (CELADON, 2014; JOHANNSON et al., 2015)

Para Chesbrough $(2003$, p. 8) "a inovação aberta é o paradigma que supõe que as empresas devem usar ideias externas da mesma forma que usam ideias internas e caminhos internos e externos para o mercado, à medida que as empresas buscam aperfeiçoamento". Essas relações permitem que se inove com ideias e recursos advindos de qualquer ambiente, desde que gere valor aos negócios e crie flexibilidade para acompanhar o mercado global. Tais recursos podem ser oriundos de consumidores, fornecedores, universidades e institutos de pesquisa (CHESBROUGH, 2003; CHESBROUGH, 2006).

Paradigmas então passam a ser quebrados: o pioneirismo não se torna algo fundamentalmente importante para uma organização (ADES et al. 2013; OLIVEIRA; ALVES, 2013); projetos que não agregam valor na organização torna-se a peça chave para outras (CHESBROUGH, 2003; LIU; ZHENG, 2011); pode-se investir financeiramente em projetos externos e até fora de seu core business (ADES et al., 2013; OLIVEIRA; ALVES, 2013), o estimulo de competências internas pode ocorrer mesmo com o avanço de controle de licenças e patentes (LINDEGAARD, 2010; SENER; HOBIKOGLU, 2013), entre outras visões definidas como necessárias ao sucesso organizacional.

Na Inovação Aberta há vários caminhos a serem percorridos até que o mercado seja atingido, ultrapassando assim as limitações físicas. Não é o caso de desconsiderar a área de P\&D (Pesquisa e Desenvolvimento), mas não a considerar como única fonte de informação e conhecimento (LINDEGAARD, 2010; STAL; OHARA; CHAGAS JUNIOR, 2014).

Esse estudo propõe a análise de cinco constructos desenvolvidos a partir de referencial teórico da pesquisa (Tabela 1): Inovação Aberta: Estabelecimento de Parcerias, Desenvolvimento de Produtos por Licenciamento e Patentes, Spin off e Spin in, Corporate Venturing e Cadeia de Valor. As sentenças apresentadas no Quadro 1 constituem o instrumento de pesquisa, também expostos nos procedimentos metodológicos.

Quadro 1- Itens do constructo de Inovação Aberta

\begin{tabular}{|c|c|c|c|}
\hline & Item & Sentenças & Autor(es) \\
\hline \multirow{3}{*}{$\begin{array}{l}\text { Estabelecim } \\
\text { ento de } \\
\text { Parcerias }\end{array}$} & EP1 & $\begin{array}{l}\text { A minha empresa busca parcerias com } \\
\text { universidades, centros de pesquisas e institutos para } \\
\text { implementar inovações. }\end{array}$ & Chesbrough $(2003 ; 2006)$ \\
\hline & EP2 & $\begin{array}{l}\text { A minha empresa busca parcerias com outras } \\
\text { empresas para captar recursos e conhecimentos. }\end{array}$ & Chesbrough $(2003 ; 2006)$ \\
\hline & EP3 & $\begin{array}{l}\text { A minha empresa já desenvolveu ou desenvolve } \\
\text { produtos em conjunto com outras empresas ou } \\
\text { instituições. }\end{array}$ & Chesbrough $(2003 ; 2006)$ \\
\hline \multirow{2}{*}{$\begin{array}{l}\text { Desenvolvim } \\
\text { ento de } \\
\text { Produtos por } \\
\text { Licenciament } \\
\text { o e Patentes }\end{array}$} & $\begin{array}{l}\text { DPLP } \\
1\end{array}$ & $\begin{array}{l}\text { A minha empresa compartilha seus equipamentos e } \\
\text { suas tecnologias com outras empresas/instituições. }\end{array}$ & $\begin{array}{l}\text { 2010) e Sener } \\
\text { (2013) }\end{array}$ \\
\hline & $\begin{array}{l}\text { DPLP } \\
2\end{array}$ & $\begin{array}{l}\text { A minha empresa recebe equipamentos e } \\
\text { tecnologias de outras empresas/instituições. }\end{array}$ & $\begin{array}{l}\text { Lindegaard (2010) e Sener } \\
\text { e Hobikoglu (2013) }\end{array}$ \\
\hline \multirow[t]{2}{*}{$\begin{array}{l}\text { Spin In } \\
\text { Spin Off }\end{array}$} & $\mathrm{SIO} 1$ & $\begin{array}{l}\text { A minha empresa cria novos negócios quando } \\
\text { detecta outras oportunidades diferentes do } \\
\text { mercado principal, investindo no desenvolvimento } \\
\text { desses projetos em paralelo. }\end{array}$ & $\begin{array}{l}\text { Ades et al. (2013); Oliveira } \\
\text { e Alves (2013). }\end{array}$ \\
\hline & $\mathrm{SIO} 2$ & $\begin{array}{l}\text { A minha empresa utiliza negócios ou produtos já } \\
\text { existentes para gerar novos negócios. }\end{array}$ & 013); Oliveira \\
\hline \multirow[b]{2}{*}{$\begin{array}{l}\text { Corporate } \\
\text { Venturing }\end{array}$} & COV1 & $\begin{array}{l}\text { É comum a minha empresa investir financeiramente } \\
\text { para a formação e, ou manutenção de centros de } \\
\text { pesquisa e desenvolvimento (P\&D) externos. }\end{array}$ & Oliveira e Alves (2013) \\
\hline & COV2 & $\begin{array}{l}\text { Financiamentos e empréstimos são feitos de } \\
\text { maneira planejada e calculada para aprimoramento } \\
\text { de centros de pesquisa e desenvolvimento da minha } \\
\text { própria empresa. }\end{array}$ & Oliveira e Alves (2013) \\
\hline $\begin{array}{l}\text { Cadeia de } \\
\text { Valor }\end{array}$ & CAV1 & $\begin{array}{l}\text { A minha empresa entende que as boas ideias podem } \\
\text { surgir de qualquer nível hierárquico e local, por isso }\end{array}$ & $\begin{array}{l}\text { Chesbrough (2003); L } \\
\text { Zheng (2011) }\end{array}$ \\
\hline
\end{tabular}




\begin{tabular}{|c|c|c|}
\hline Item & Sentenças & Autor(es) \\
\hline & $\begin{array}{l}\text { mantem relacionamentos com seus colaboradores, } \\
\text { fornecedores, clientes e concorrentes. }\end{array}$ & \\
\hline CAV2 & $\begin{array}{l}\text { A minha empresa propôs ou propõe soluções para } \\
\text { problemas dos parceiros que constituem a cadeia de } \\
\text { valor (Fornecedores, Clientes, Concorrentes e } \\
\text { Colaboradores). }\end{array}$ & $\begin{array}{l}\text { Chesbrough (2003); Liu e } \\
\text { Zheng (2011) }\end{array}$ \\
\hline CAV3 & $\begin{array}{l}\text { A minha empresa recebeu ou recebe soluções para } \\
\text { problemas dos parceiros que constituem a cadeia de } \\
\text { valor (Fornecedores, Clientes, Concorrentes e } \\
\text { Colaboradores). }\end{array}$ & $\begin{array}{l}\text { Chesbrough (2003); Liu e } \\
\text { Zheng (2011) }\end{array}$ \\
\hline CAV4 & $\begin{array}{l}\text { Quando uma ideia não é considerada importante } \\
\text { para a minha empresa, ela é compartilhada com os } \\
\text { atores da cadeia de valor (Fornecedores, Clientes, } \\
\text { Concorrentes e Colaboradores), para que possa ser } \\
\text { utilizada e desenvolvida em outro local. }\end{array}$ & $\begin{array}{l}\text { Ades et al. (2013); Oliveira } \\
\text { e Alves (2013). }\end{array}$ \\
\hline CAV5 & $\begin{array}{l}\text { Os aspectos de competitividade da minha empresa } \\
\text { foram gerados a partir das relações na cadeia de } \\
\text { valor (Fornecedores, Clientes, Concorrentes e } \\
\text { Colaboradores). }\end{array}$ & $\begin{array}{l}\text { Chesbrough (2003); Liu e } \\
\text { Zheng (2011) }\end{array}$ \\
\hline
\end{tabular}

Fonte: Adaptado de Chesbrough (2003), Chesbrough, (2006), Lindegaard (2010), Liu e Zheng (2011) e Sener e Hobikoglu (2013).

A partir da Inovação Aberta as organizações mantêm relacionamentos e criam laços interorganizacionais duradouros. Os envolvidos possuem interesses particulares e comuns, contribuindo para a criação e difusão de novos produtos, serviços e mercados (ADES et al., 2013). Por meio da integração com atores internos e externos à empresa, uma complementariedade de competências, acessos às informações e aprendizado coletivo suprem as lacunas e déficits que as organizações buscam aprimorar (BONNER; BAUMANN, 2012; SIE et al., 2014).

A forma e a viabilidade das redes de conhecimento estabelecem as práticas de transferência e aquisição de recursos e definem a potencialidade atingida. As redes, quando bem definidas e viáveis, permitem um elevado grau de envolvimento, crescimento coletivo e prática contínua da construção do conhecimento (DESIDERIO; POPADIUK, 2015; MASSAINI; OLIVA, 2015; GUAN; LIU, 2016).

O ambiente, os recursos disponíveis e a forma com que a inovação é visualizada, também influenciam diretamente a aplicação desse tipo de inovação nas organizações (HEREDERO; SANTOS; EQUILAZ, 2013; CHESBROUGH, 2006). Para a prática da inovação aberta é necessário que a organização possua uma cultura propícia à inovação e que estimule as relações e trocas com o meio externo.

Salienta-se que apenas buscar recursos externos não torna a prática eficiente e recursos internos, como portfólios, a capacidade absortiva, os próprios recursos de P\&D, as formas com que as lideranças e a própria empresa investem em inovação e nas práticas de inovação aberta, devem ser considerados (RODRIGUES; MACCARI; CAMPANARIO, 2010).

Chesbrough (2006), Pitassi (2012) e Saebi e Foz (2015) discutem que quando se define bem as estratégias e mantêm relacionamentos adequados, reconhece-se adequadamente o que se necessita do meio externo e sabe-se o que se pode fornecer. O modelo de inovação aberta abrange dois aspectos propulsores e necessários para sua prática: as redes de conhecimento e o perfil inovador das organizações.

Para esse estudo, o instrumento de pesquisa para os constructos Redes de Conhecimento e Perfil de Inovação Organizacional é mostrado no Quadro 2. 
Quadro 2- Itens dos constructos de Redes de Conhecimento e Perfil Inovador Organizacional

\begin{tabular}{|c|c|c|c|}
\hline & Item & Sentenças & Autor(es) \\
\hline \multirow{3}{*}{$\begin{array}{l}\text { Redes de } \\
\text { Conhecimento }\end{array}$} & $\mathrm{RC} 1$ & $\begin{array}{l}\text { Minha empresa estabelece relação com outras } \\
\text { empresas para troca de informações. }\end{array}$ & Sie et al. (2014) \\
\hline & $\mathrm{RC} 2$ & $\begin{array}{l}\text { Minha empresa estabelece relação entre as áreas e os } \\
\text { colaboradores da própria empresa para troca de } \\
\text { informações e conhecimento. }\end{array}$ & Sie et al. (2014) \\
\hline & $\mathrm{RC} 3$ & $\begin{array}{l}\text { As empresas com as quais a minha empresa mantêm } \\
\text { contatos são confiáveis para o compartilhamento de } \\
\text { informações. }\end{array}$ & $\begin{array}{l}\text { Desiderio e Popadiuk } \\
\text { (2015); Guan e Liu } \\
\text { (2016). }\end{array}$ \\
\hline \multirow{10}{*}{ Perfil Inovador } & PIN1 & $\begin{array}{l}\text { A minha empresa descreve em seu planejamento } \\
\text { estratégico as práticas de inovação que são utilizadas } \\
\text { pela organização. }\end{array}$ & $\begin{array}{l}\text { Pitassi (2012); Saebi e } \\
\text { Foz (2015) }\end{array}$ \\
\hline & PIN2 & $\begin{array}{l}\text { Na minha empresa os funcionamentos e as estratégias } \\
\text { de negócio para as práticas de inovação são conhecidos } \\
\text { por todos os colaboradores. }\end{array}$ & $\begin{array}{l}\text { Pitassi (2012); Saebi e } \\
\text { Foz (2015) }\end{array}$ \\
\hline & PIN3 & $\begin{array}{l}\text { A minha empresa promove ou promoveu adaptação na } \\
\text { cultura interna para melhor atuar no campo da } \\
\text { inovação. }\end{array}$ & $\begin{array}{l}\text { Heredero, Santos e } \\
\text { Equilaz, (2013) }\end{array}$ \\
\hline & PIN4 & $\begin{array}{l}\text { Existe facilidade de acesso, relacionamento e } \\
\text { confiabilidade entre os colaboradores e os líderes da } \\
\text { minha empresa quando se busca a inovação. }\end{array}$ & $\begin{array}{l}\text { Rodrigues, Maccari e } \\
\text { Campanario, (2010) }\end{array}$ \\
\hline & PIN5 & $\begin{array}{l}\text { O ambiente da minha empresa é propício e está pronto } \\
\text { para estimular a inovação. }\end{array}$ & $\begin{array}{l}\text { Heredero, Santos e } \\
\text { Equilaz, (2013) }\end{array}$ \\
\hline & PIN6 & $\begin{array}{l}\text { Na minha empresa, os colaboradores de todas as áreas } \\
\text { são incentivados a darem sugestões e ideias para os } \\
\text { negócios. }\end{array}$ & $\begin{array}{l}\text { Rodrigues, Maccari e } \\
\text { Campanario, (2010) }\end{array}$ \\
\hline & PIN6 & $\begin{array}{l}\text { A minha empresa possui um planejamento de } \\
\text { investimento em inovação formalizado em médio e } \\
\text { longo prazo. }\end{array}$ & $\begin{array}{l}\text { Pitassi (2012); Saebi e } \\
\text { Foz (2015) }\end{array}$ \\
\hline & PIN7 & $\begin{array}{l}\text { Quando se trata de inovação, a minha empresa tem a } \\
\text { percepção clara dos pontos a serem melhorados } \\
\text { internamente. }\end{array}$ & Chesbrough (2006) \\
\hline & PIN8 & $\begin{array}{l}\text { Quando se trata de inovação, a minha empresa tem a } \\
\text { percepção clara dos pontos fortes que apresenta } \\
\text { perante o mercado. }\end{array}$ & Chesbrough (2006) \\
\hline & PIN9 & $\begin{array}{l}\text { Na minha empresa existe uma estrutura interna de } \\
\text { pesquisa, desenvolvimento e inovação. }\end{array}$ & Chesbrough (2006) \\
\hline
\end{tabular}

Fonte: Adaptado de Chesbrough (2006), Rodrigues, Maccari e Campanario, (2010), Pitassi (2012),

Heredero, Santos e Equilaz, (2013), Sie et al. (2014) e Saebi e Foz (2015).

As sentenças apresentadas por meio da Tabela 2 constituem o instrumento de pesquisa deste estudo, conforme exposto na seção de procedimentos metodológicos dessa pesquisa.

\section{A CRIAÇÃO DE VALOR COMO OBJETIVO DA INOVAÇÃO ABERTA}

A identificação dos fatores de inovação aberta relacionados à Criação de Valor é o objetivo principal de uma organização. As organizações tornam-se capazes de gerar resultados e desenvolver o capital humano por meio da criatividade e estímulos às novas ideias. Para Oliveira e Alves (2013, p. 299), a Criação de Valor "envolve inovação que cria ou aumenta a valorização dos benefícios do consumo", seja pelo aumento da produtividade, seja pelo aumento da rentabilidade, criando novos produtos ou ganhando novos mercados. 
As organizações criam valor quando relacionam os recursos e o conhecimento com a capacidade de inovar, reagindo ao ambiente externo e se posicionando mercadologicamente. Tais recursos podem se apresentar de três maneias (ROMAM et al., 2012; ARAUJO; MOTTIN; REZENDE, 2013);: (i) tangível, caracterizados pela parte financeira e física (ii) intangível caracterizados pela qualidade do produto, pela inteligência dos colaboradores e pela marca da organização, ou; (iii) capacidade organizacional, representada pelas rotinas, processos e cultura organizacional.

Salienta-se que as estratégias financeiras e os recursos tangíveis isolados não são suficientes para a mensuração do valor das organizações (HERRERA, 2015) e "o conhecimento emerge como um dos recursos estratégicos mais importantes para as empresas" que possuem expectativas referentes ao lucro e a manutenção no mercado (OLIVEIRA; ALVES, 2013, p. 9).

O valor só é realmente gerado quando os recursos são empregados e utilizados de forma apropriada dentro do ambiente empresarial e conseguem atender as expectativas dos parceiros produtivos e do público consumidor (BRITO; BRITO, 2012; SIRMON; HITT; IRELAND, 2014; OH TEAK et al., 2015). A Criação de Valor, quando encarado como base de competitividade, agrega a capacidade de manobras e estratégias e permite que a organização acompanhe o mercado e cresça de forma superior às demais organizações

Para compor o constructo Criação de Valor têm-se os instrumentos do Quadro 3.

Quadro 3- Itens do constructo de Criação de Valor

\begin{tabular}{|c|c|c|c|}
\hline & Item & Sentença & Autor(es) \\
\hline \multirow{9}{*}{$\begin{array}{l}\text { Criação } \\
\text { de } \\
\text { Valor }\end{array}$} & CV1 & $\begin{array}{l}\text { Em algum aspecto a competitividade da minha empresa foi } \\
\text { gerada a partir das relações com as outras empresas. }\end{array}$ & $\begin{array}{l}\text { Chesbrough, } \\
(2006)\end{array}$ \\
\hline & CV2 & $\begin{array}{l}\text { Minha empresa é mais competente e segura por manter } \\
\text { relacionamentos e trocar informações com outras empresas. }\end{array}$ & $\begin{array}{l}\text { Chesbrough, } \\
(2006)\end{array}$ \\
\hline & CV3 & $\begin{array}{l}\text { A minha empresa já obteve ou obtêm ganhos financeiros ou em } \\
\text { produtividade, em função das parcerias entre universidades, } \\
\text { institutos e centros de pesquisa. }\end{array}$ & $\begin{array}{l}\text { Chesbrough, } \\
(2006)\end{array}$ \\
\hline & CV4 & $\begin{array}{l}\text { A minha empresa já obteve ou obtêm ganhos financeiros ou em } \\
\text { produtividade, ao desenvolver produtos com outras empresas ou } \\
\text { instituições. }\end{array}$ & $\begin{array}{l}\text { Lindegaard (2010) } \\
\text { e Sener e } \\
\text { Hobikoglu (2013) }\end{array}$ \\
\hline & CV5 & $\begin{array}{l}\text { A minha empresa gera ganhos em função do compartilhamento } \\
\text { ou recebimento de equipamentos e tecnologias. }\end{array}$ & $\begin{array}{l}\text { Ades et al. (2013); } \\
\text { Oliveira e Alves } \\
\text { (2013). }\end{array}$ \\
\hline & CV6 & $\begin{array}{l}\text { A minha empresa já obteve ou obtêm ganhos em } \\
\text { competitividade ou produtividade quando investe em outros } \\
\text { projetos diferentes do mercado principal de produtos ou } \\
\text { negócios já existentes. }\end{array}$ & $\begin{array}{l}\text { Ades et al. (2013); } \\
\text { Oliveira e Alves } \\
\text { (2013). }\end{array}$ \\
\hline & CV7 & $\begin{array}{l}\text { A minha empresa obteve ou obtêm ganhos em competitividade } \\
\text { ou produtividade investindo em outros negócios, originados de } \\
\text { produtos ou negócios já existentes. }\end{array}$ & $\begin{array}{l}\text { Ades et al. (2013); } \\
\text { Oliveira e Alves } \\
\text { (2013). }\end{array}$ \\
\hline & CV8 & $\begin{array}{l}\text { A minha empresa gera ganhos em função das práticas de } \\
\text { obtenção ou fornecimento de investimentos financeiros. }\end{array}$ & $\begin{array}{l}\text { Chesbrough } \\
\text { (2003); Liu e } \\
\text { Zheng (2011) }\end{array}$ \\
\hline & CV9 & $\begin{array}{l}\text { A minha empresa obteve ou obtêm diferenciais competitivos e } \\
\text { valor em função das ações colaborativas com a cadeia de valor } \\
\text { (Fornecedores, Clientes, Concorrentes e Colaboradores). }\end{array}$ & $\begin{array}{l}\text { Chesbrough } \\
\text { (2003); Liu e } \\
\text { Zheng (2011) }\end{array}$ \\
\hline
\end{tabular}




\section{METODOLOGIA}

O presente estudo se caracteriza como uma pesquisa com abordagem quantitativa-descritiva (VERGARA, 2015). Para atender ao objetivo dessa pesquisa, que se propõe a determinar quais fatores que constituem a inovação aberta influenciam a criação de valor para as Empresas de Base Tecnológica, optou-se por realizar a coleta de dados por meio de questionário estruturado do tipo survey, com escala do tipo likert de cinco pontos. A escala foi padronizada subtraindo do valor original o valor central 3 e em seguida o resultado foi dividido por 2 para que oscilasse de -1 a 1 .

O questionário possui 45 questões, sendo 36 questões relacionadas os constructos: Redes de Conhecimento, Inovação, Estabelecimento de Parcerias, Desenvolvimento de Produtos por Licenciamento e Patentes, Spin off e Spin in, Corporate Venturing e Cadeia de Valor e 8 questões caracterizadoras dos respondentes. Realizou-se um pré-teste com 10 colaboradores de EBTs e 2 docentes das áreas de pesquisa inovação e gestão do conhecimento.

O universo da pesquisa é composto por colaboradores de EBTs brasileiras, independentemente da solução tecnológica proposta pela organização. Para a composição da amostra utilizou-se a técnica de snowball, que segundo Baldin e Munhoz (2011, p.332), "é uma forma de amostra não probabilística [...] em que os participantes iniciais de um estudo indicam novos participantes que por sua vez indicam novos participantes e assim sucessivamente", valendo-se da propagação de respondentes por meio da indicação pelos próprios participantes da pesquisa.

Ao total foram obtidas 466 respostas, sendo desconsideradas 111 por apresentarem mais de $10 \%$ de dados faltantes. Houve 355 respostas válidas. Salienta-se que devido a técnica escolhida, não há mensuração exata das empresas participantes do estudo, bem como caracterização do colaborador por empresa.

Para a qualidade das respostas dos questionários foi analisada a existência dos outliers. Para descrever as variáveis caracterizadoras da amostra foram utilizadas as frequências absolutas e relativas. Já na descrição dos itens dos constructos utilizou-se medidas de tendência central e dispersão. Devido à presença de constructos de segunda ordem, foi utilizada a abordagem Two-Step.

Para testar os modelos teóricos hipotéticos foi utilizada a modelagem de equações estruturais via abordagem Partial Least Square (PLS) (Vinzi et al., 2010). O modelo de mensuração por meio de pesos e o modelo dos coeficientes foram comparados. Todos os constructos apresentaram índice de CC acima de 0,7, foram unidimensionais pelo método Parallel Analysise apresentam AVE superior a 0,40.

Os dados apontam que há um índice validado que represente os constructos perfil inovador, redes de conhecimento e inovação aberta, por meio da média dos itens apresentados. Destaca-se que todos os itens apresentaram cargas fatoriais acima de 0,50 e os intervalos de confiança (I.C. - 95\%), o que evidencia a significância de os pesos e a relevância dos itens para a formação do indicador que representará o constructo. O software utilizado para as análises estatísticas foi o R (versão 3.1.3).

\section{APRESENTAÇÃO E ANÁLISE DOS RESULTADOS}

Em primeira instância, para compreensão dos resultados e do perfil dos respondentes, preocupa-se em realizar uma análise descritiva da amostra, caracterizando as empresas, o grau de envolvimento e atuação dos respondentes bem como seu nível de escolaridade. A pesquisa foi composta por 355 respondentes válidos, dos quais 55, 51\% atuam a mais de 1 ano nas áreas de inovação e P\&D de produtos/serviços e possuem como grau de escolaridade o nível superior (36,34\%). Essas caracterizações enfatizam a credibilidade da pesquisa ao afirmar que os respondentes vivenciam práticas diárias de inovação nas empresas e possuem conhecimento para respondê-las.

Ao verificar as organizações pesquisadas, aproximadamente $80 \%$ são do setor privado e atuantes no estado brasileiro de Minas Gerais a mais de 10 anos (50,99\%). São empresas, em sua maioria, caracterizadas pelos segmentos aeroespacial, farmacêutico, de informática, eletrônica, telecomunicações e instrumentos (52\%) e que apresentam, de acordo com a OCDE (2005), uma alta intensidade tecnológica. 
Quanto ao tipo de inovação 43\% das empresas se baseiam em tecnologia consolidada de nicho de mercado, conforme Figura 1, e evidenciam que as EBTs, principalmente as Brasileiras, se concentram na realização de esforços tecnológicos para fabricação de produtos "incrementais" provenientes da imitação e adaptação (PINHO et al., 2005) e ainda inovam pouco radicalmente.

Figura 1- Classificação das empresas quanto ao tipo de inovação

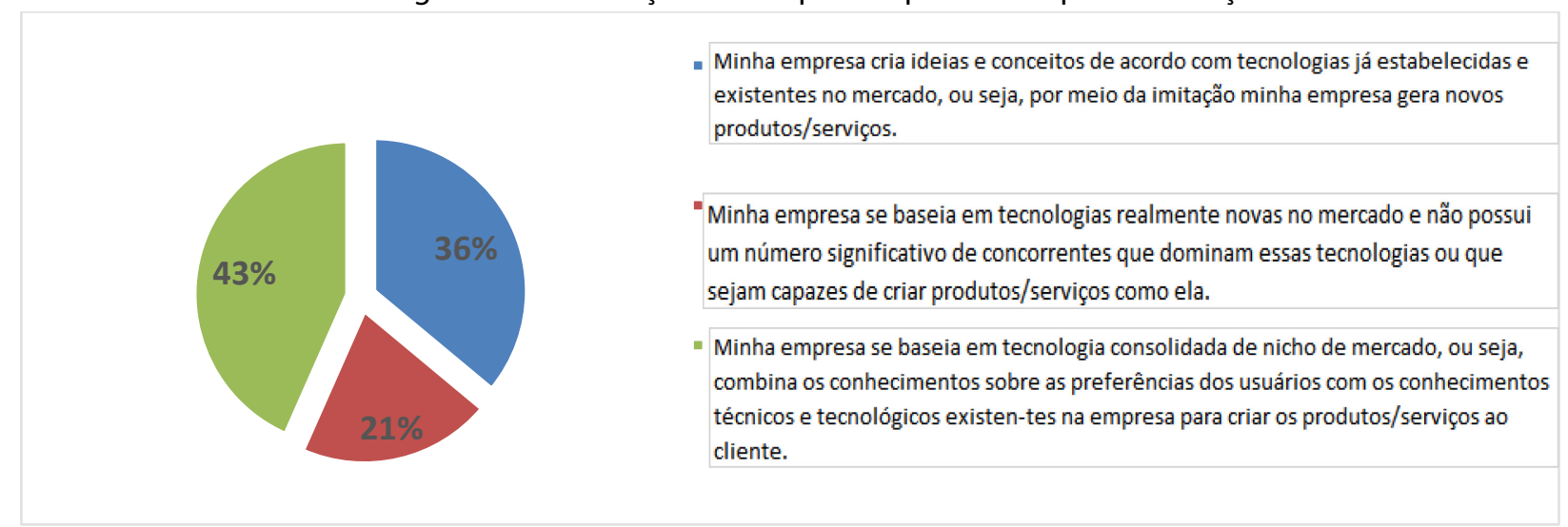

Fonte: Dados da Pesquisa (2017).

O resultado dessa pesquisa vem ao encontro das afirmações de Pinho et al. (2005) e Santos e Pinho (2010), quando enfatiza que as EBTs procuram combinar conhecimentos das preferências de seus clientes/usuários com habilidades que desenvolve internamente, para que novos produtos sejam criados por meio de inovações incrementais. As inovações incrementais ainda são pontos focais das organizações Brasileiras.

Ao realizar uma análise descritiva dos constructos, foi encontrada uma tendência significativa dos respondentes a concordar com todos os itens do constructo perfil inovador. Entretanto os itens "Na minha empresa os funcionamentos e as estratégias de negócio para as práticas de inovação são conhecidos por todos os colaboradores" (PI2) e "Na minha empresa, os colaboradores de todas as áreas são incentivados a darem sugestões e ideias para os negócios" (PI6) apresentaram diferença na escala de concordância, apesar de estarem com valores aproximados, conforme Quadro 4.

Quadro 4- Intervalo de confiança do constructo de perfil inovador

\begin{tabular}{l|l|c|c}
\hline Constructo & Sentença & Média & IC - 95\%* \\
\hline \multirow{5}{*}{$\begin{array}{l}\text { Perfil } \\
\text { Inovador }\end{array}$} & $\begin{array}{l}\text { PI1- A minha empresa descreve em seu planejamento } \\
\text { estratégico as práticas de inovação que são utilizadas pela } \\
\text { organização. }\end{array}$ & 0,12 & {$[0,11 ; 0,13]$} \\
\cline { 2 - 4 } & $\begin{array}{l}\text { PI2- Na minha empresa os funcionamentos e as estratégias } \\
\text { de negócio para as práticas de inovação são conhecidos por } \\
\text { todos os colaboradores. }\end{array}$ & 0,12 & {$[0,11 ; 0,13]$} \\
\cline { 2 - 4 } & $\begin{array}{l}\text { PI3- A minha empresa promove ou promoveu adaptação na } \\
\text { cultura interna para melhor atuar no campo da inovação. }\end{array}$ & 0,14 & {$[0,13 ; 0,15]$} \\
\hline & $\begin{array}{l}\text { PI4- Existe facilidade de acesso, relacionamento e } \\
\text { confiabilidade entre os colaboradores e os líderes da minha } \\
\text { empresa quando se busca a inovação. }\end{array}$ & 0,12 & {$[0,11 ; 0,13]$} \\
\hline & $\begin{array}{l}\text { PI5- O ambiente da minha empresa é propício e está pronto } \\
\text { para estimular a inovação. }\end{array}$ & 0,12 & {$[0,11 ; 0,13]$} \\
\hline & $\begin{array}{l}\text { PI6- Na minha empresa, os colaboradores de todas as áreas } \\
\text { são incentivados a darem sugestões e ideias para os } \\
\text { negócios. }\end{array}$ & 0,13 & {$[0,12 ; 0,13]$} \\
\hline
\end{tabular}




\begin{tabular}{l|l|c|c}
\hline Constructo & Sentença & Média & IC - 95\%* \\
\hline & $\begin{array}{l}\text { PI7- A minha empresa possui um planejamento de } \\
\text { investimento em inovação formalizado em médio e longo } \\
\text { prazo. }\end{array}$ & 0,13 & {$[0,12 ; 0,14]$} \\
\hline $\begin{array}{l}\text { PI8- Quando se trata de inovação, a minha empresa tem a } \\
\text { percepção clara dos pontos a serem melhorados } \\
\text { internamente. }\end{array}$ & 0,14 & {$[0,13 ; 0,15]$} \\
\hline $\begin{array}{l}\text { PI9- Quando se trata de inovação, a minha empresa tem a } \\
\text { percepção clara dos pontos fortes que apresenta perante o } \\
\text { mercado. }\end{array}$ & 0,13 & {$[0,12 ; 0,14]$} \\
\hline $\begin{array}{l}\text { PI10- Na minha empresa existe uma estrutura interna de } \\
\text { pesquisa, desenvolvimento e inovação. }\end{array}$ & 0,14 & {$[0,13 ; 0,15]$} \\
\hline
\end{tabular}

Fonte: Dados da pesquisa (2017).

O tipo de segmento pesquisado já traz em seu conceito os parâmetros de inovação. Para Santos e Pinho (2010) as EBTs possuem uma intensidade inovativa capaz de sustentar competências técnicas sólidas e apresentar uma elevada expectativa de crescimento. Porém, para que haja uma intensidade inovativa considerável e real, todos os colaboradores de uma organização precisam estar envolvidos, de maneira que ideias possam surgir de qualquer nível hierárquico ou ambiente (CHEN et al., 2015).

Dessa forma, em um processo de inovação faz-se necessária uma comunicação clara dos objetivos da inovação e o reconhecimento das oportunidades e recompensas por parte dos colaboradores. Somente assim, as atividades que tragam novas ideias, técnicas e métodos serão estimuladas e a força de trabalho será diretamente proporcional ao desempenho das atividades (CHEN; HUANG, 2010). O colaborador se sentindo parte da empresa assumirá a responsabilidade pela eficácia de suas ações.

Em relação ao constructo redes de conhecimento, em média, houve uma tendência significativa dos respondentes a concordarem com todos os itens. Houve uma maior tendência de concordar com o item "Minha empresa estabelece relação entre as áreas e os colaboradores da própria empresa para troca de informações e conhecimento" (RC2) (Quadro 5). Esse resultado reforça a importância em se manter laços para compartilhamento de recursos e soluções

Quadro 5- Intervalo de confiança do constructo de Redes de Conhecimento

\begin{tabular}{|c|c|c|c|}
\hline Constructo & Sentença & Média & IC - 95\%* \\
\hline \multirow{3}{*}{$\begin{array}{l}\text { Redes de } \\
\text { Conhecimento }\end{array}$} & $\begin{array}{l}\text { RC1 Minha empresa estabelece relação com outras empresas } \\
\text { para troca de informações e conhecimento. }\end{array}$ & 0,44 & {$[0,42 ; 0,48]$} \\
\hline & $\begin{array}{l}\text { RC2 Minha empresa estabelece relação entre as áreas e os } \\
\text { colaboradores da própria empresa para troca de informações } \\
\text { e conhecimento. }\end{array}$ & 0,36 & {$[0,33 ; 0,39]$} \\
\hline & $\begin{array}{l}\text { RC3 As empresas com as quais a minha empresa mantêm } \\
\text { contatos são confiáveis para o compartilhamento de } \\
\text { informações. }\end{array}$ & 0,40 & {$[0,36 ; 0,43]$} \\
\hline
\end{tabular}

Fonte: Dados da pesquisa (2017).

A formação de redes de conhecimento permite que informações e experiências sejam compartilhadas e sirvam como fonte de valor. Por meio das redes, ideias originam novos produtos, processos e descobertas (SCHMID; KNIERIM; KNUTH, 2016) e as incertezas do processo de inovação são compartilhadas e reduzidas. Apesar de haver uma tendência positiva em todos os itens, a formação de parcerias com empresas ainda é inferior às demais parcerias.

Nonaka e Takeuchi (2008) defendem que o conhecimento não ocorre apenas dentro da organização, mas também por meio de conexões externas, o que inclui empresas privadas. Nesse sentido, as EBTs pesquisadas aprimoram as suas relações com outras empresas e estão conscientes de que as diversidades nos tipos de parceiros de uma rede apoiam os diferentes tipos de desempenho em inovação. 
Quanto aos itens de inovação aberta, avaliou-se cada constructo de primeira ordem. Para o constructo o "Estabelecimento de Parcerias", conforme Tabela 6, houve em média uma tendência significativa dos respondentes a concordarem com todos os itens. Apenas o item "A minha empresa busca parcerias com universidades, centros de pesquisas e institutos para implementar inovações (EP1)" apresentou uma menor tendência entre as escalas de concordância.

A concordância na maioria dos itens relacionados remete mais uma vez, ao reconhecimento da oportunidade que existe quando parcerias são mantidas. Chama-se a atenção à contradição encontrada nas respostas. Ao se relatar o constructo "Redes de Conhecimento", encontrou-se, com menor incidência, a relação entre empresas. Massaini e Oliva (2015) já salientavam que ainda é constante a centralização dos processos de inovação, acarretando a falta de consciência dos benefícios proporcionados pelo estabelecimento de parcerias. Esse pode ser um motivo da distinção dos resultados.

Para o constructo "Desenvolvimento de Produtos por Licenciamento e Patentes" também houve uma tendência significativa a concordar para o item "A minha empresa A minha empresa recebe equipamentos e tecnologias de outras empresas/instituições (DPLP2)". Já o item "A minha empresa compartilha seus equipamentos e suas tecnologias com outras empresas/instituições. (DPLP1) " não apresentou informações suficientes que confirmem uma concordância ou discordância (Quadro 6).

Quadro 6 - Intervalo de confiança dos constructos de Estabelecimento de Parcerias e Desenvolvimento de Produtos por Licenciamento e Patentes

\begin{tabular}{l|l|c|c}
\hline Constructo & Sentença & Média & IC - 95\%* \\
\hline \multirow{2}{*}{$\begin{array}{l}\text { Estabelecimento } \\
\text { de Parcerias }\end{array}$} & $\begin{array}{l}\text { EP1 A minha empresa busca parcerias com universidades, } \\
\text { centros de pesquisas e institutos para implementar inovações. }\end{array}$ & 0,08 & {$[0,01 ; 0,15]$} \\
\cline { 2 - 4 } & $\begin{array}{l}\text { EP2 A minha empresa busca parcerias com outras empresas } \\
\text { para captar recursos e conhecimentos. }\end{array}$ & 0,18 & {$[0,12 ; 0,24]$} \\
\cline { 2 - 4 } & $\begin{array}{l}\text { EP3 A minha empresa já desenvolveu ou desenvolve produtos } \\
\text { em conjunto com outras empresas ou instituições. }\end{array}$ & 0,15 & {$[0,09 ; 0,22]$} \\
\cline { 2 - 4 } $\begin{array}{l}\text { Desenvolviment } \\
\text { o de Produtos } \\
\text { por } \\
\text { Licenciamento e } \\
\text { Patentes }\end{array}$ & $\begin{array}{l}\text { DPLP1 A minha empresa compartilha seus equipamentos e } \\
\text { suas tecnologias com outras empresas/instituições. }\end{array}$ & 0,03 & {$[-0,04 ; 0,09]$} \\
\cline { 2 - 4 } & $\begin{array}{l}\text { DPLP2 A minha empresa recebe equipamentos e tecnologias } \\
\text { de outras empresas/instituições. }\end{array}$ & 0,12 & {$[0,05 ; 0,19]$} \\
\hline
\end{tabular}

Fonte: Dados da pesquisa (2017).

A Inovação Aberta propõe uma democratização dos processos de inovação, de maneira que capacidades, recursos e tecnologias sejam adquiridos e também transferidos, criando o que se chama de "caminho de mão dupla" para a inovação (CHEN, 2014). O que se observa nas EBTs pesquisadas é que a utilização da Inovação Aberta como transferência de recursos se sobressai perante a Inovação Aberta para aquisição de recursos. $O$ resultado demonstra uma validação dos estudos contidos na literatura, que foram até então realizados. Os estudos de Rodrigues, Maccari e Campanario (2010) e Desiderio e Popadiuk (2015) ao apresentarem uma análise das empresas Brasileiras, apontam a sobressalência da aquisição de equipamentos e, ou tecnologias por parte das empresas. Resultado esse, também identificado nessa pesquisa.

O uso colaborativo de tecnologias implica em maior quantidade de criação e pesquisas de ideias inovadoras. Quanto mais rapidamente uma tecnologia sair dos limites de um laboratório, tanto mais rapidamente surgirão formas de aplicar, equilibrar e integrar aquela tecnologia a novos produtos (CHESBROUGH, 2006; FLORES et al., 2015; GUAN; LIU, 2016). Essa é uma oportunidade aproveitada pelas empresas pesquisadas. Mas receber novas tecnologias possibilitaria também que capacidades e conhecimentos externos fossem agregados internamente e permitiria visões distintas sobre um processo, solucionando problemas e preenchendo lacunas organizacionais.

Com relação ao constructo Spin in e Spin off, a tendência significativa a concordar com todos os itens também ocorreu (Tabela 7). O item "A minha empresa utiliza negócios ou produtos já existentes no mercado para gerar novos negócios (SIO2)" apresentou um maior nível de concordância significativamente maior. No 
mercado, é comum que as organizações busquem negócios e, ou, produtos externos, e os agrupem aos modelos de negócio, estratégias e produção. Da mesma forma, é comum também encontrar oportunidades internas, advindas de projetos diferentes do original. Moreira et al. (2008) explicam que a importância das ideias e, ou, negócios, pode variar de uma organização para a outra. Projetos que não apresentam vantagem ou interesse para uma empresa originam novos negócios e expansão de mercado para outra e, por isso, são agrupados ou desenvolvidos paralelamente.

Salienta-se que o constructo Spin off já é constante nos modelos de Inovação Aberta apresentados por Oliveira e Alves (2013) e Saebi e Foss (2015), observando que também é constante nas empresas pesquisadas. Porém, o Spin In ainda não é um constructo comum nos modelos relacionados ao estudo da Inovação Aberta, permitindo que a proposta deste estudo seja complementar às teorias encontradas. Isso pode ser observado pelos tipos de inovações realizadas pelas empresas, uma vez que a incremental ainda é prática recorrente.

Para o constructo "Corporate Venturing" (QUADRO 7) o resultado foi neutro, não havendo concordância nem discordância dos itens. Por um lado, reconhece-se que as fronteiras de centros de pesquisas e desenvolvimentos são rompidas quando se trata da inovação aberta. Por outro lado, salienta-se que um P\&D não deve ser desconsiderado quando se aplica esse tipo de inovação. O corporate venturing é uma forma de investimento e aplicação de capital em negócios que apresentem potencial de crescimento e, ou embrionários. Como os itens de Corporate Venturing não apresentaram em seus resultados uma tendência significativa a concordar ou discordar das questões, percebe-se que esse tipo de investimento deva ser mais bem discutido pelas EBTs em questão.

Quadro 7 - Intervalo de confiança dos constructos de Spin In e Spin Offe Corporate Venturing

\begin{tabular}{l|l|l|l}
\hline Constructo & Itens & Média & IC - 95\%* \\
\hline \multirow{3}{*}{$\begin{array}{l}\text { Spin in e } \\
\text { Spin off }\end{array}$} & $\begin{array}{l}\text { SIO1 A minha empresa cria novos negócios quando detecta outras } \\
\text { oportunidades diferentes do mercado principal, investindo no } \\
\text { desenvolvimento desses projetos em paralelo. }\end{array}$ & 0,19 & {$[0,13 ; 0,25]$} \\
\cline { 2 - 3 } & $\begin{array}{l}\text { SIO2 A minha empresa utiliza negócios ou produtos já existentes } \\
\text { para gerar novos negócios. }\end{array}$ & 0,34 & {$[0,28 ; 0,40]$} \\
\hline $\begin{array}{l}\text { COV1 É comum a minha empresa investir financeiramente para a } \\
\text { formação e, ou manutenção de centros de pesquisa e } \\
\text { Venturing } \\
\text { desenvolvimento (P\&D) externos. }\end{array}$ & $\begin{array}{l}\text { COV2 Financiamentos e empréstimos são feitos de maneira } \\
\text { planejada e calculada para aprimoramento de centros de } \\
\text { pesquisa e desenvolvimento da minha própria empresa. }\end{array}$ & 0,07 & {$[-0,06 ; 0,07]$} \\
\hline
\end{tabular}

Fonte: Dados da pesquisa (2017).

Investir em P\&D, sejam internos ou externos, permite que o capital intelectual capacitado e criativo seja agregado às organizações para que vantagens sejam adquiridas (VELIC; MARJANOVIC, 2016). Para inovar, é necessário investimento em departamentos de pesquisa e inovação. Essa resposta é reflexo do item "inovação", em que foi visto que não há uma comunicação clara dos processos inovativos. O constructo "Cadeia de Valor" apresentou uma tendência significativa, com exceção do item "Quando uma ideia não é considerada importante para a minha empresa, ela é compartilhada com os atores da cadeia de valor (Fornecedores, Clientes, Concorrentes e Colaboradores) para que possa ser utilizada e desenvolvida em outro local (CAV4)" (Quadro 8). 
Quadro 8 - Intervalo de confiança do constructo de Cadeia de Valor

\begin{tabular}{|c|c|c|c|}
\hline Constructo & Sentença & Média & IC - 95\%* \\
\hline \multirow{5}{*}{$\begin{array}{l}\text { Cadeia de } \\
\text { Valor }\end{array}$} & $\begin{array}{l}\text { CAV1 A minha empresa entende que as boas ideias podem surgir } \\
\text { de qualquer nível hierárquico e local, por isso mantem } \\
\text { relacionamentos com seus colaboradores, fornecedores, clientes e } \\
\text { concorrentes. }\end{array}$ & 0,29 & {$[0,23 ; 0,36]$} \\
\hline & $\begin{array}{l}\text { CAV2 A minha empresa propôs ou propõe soluções para problemas } \\
\text { dos parceiros que constituem a cadeia de valor (Fornecedores, } \\
\text { Clientes, Concorrentes e Colaboradores). }\end{array}$ & 0,23 & {$[0,17 ; 0,29]$} \\
\hline & $\begin{array}{l}\text { CAV3 A minha empresa recebeu ou recebe soluções para } \\
\text { problemas dos parceiros que constituem a cadeia de valor } \\
\text { (Fornecedores, Clientes, Concorrentes e Colaboradores). }\end{array}$ & 0,24 & {$[0,18 ; 0,30]$} \\
\hline & $\begin{array}{l}\text { CAV4 Quando uma ideia não é considerada importante para a } \\
\text { minha empresa, ela é compartilhada com os atores da cadeia de } \\
\text { valor (Fornecedores, Clientes, Concorrentes e Colaboradores) para } \\
\text { que possa ser utilizada e desenvolvida em outro local. }\end{array}$ & 0,05 & {$[-0,01 ; 0,11]$} \\
\hline & $\begin{array}{l}\text { CAV5 Os Aspectos de competitividade da minha empresa foram } \\
\text { gerados a partir das relações na cadeia de valor (Fornecedores, } \\
\text { Clientes, Concorrentes e Colaboradores). }\end{array}$ & 0,21 & {$[0,14 ; 0,27]$} \\
\hline
\end{tabular}

Fonte: Dados da pesquisa (2017).

Por meio do resultado positivo, é enfatizada a importância da relação entre a organização e os atores que compõem a cadeia de valor. Chama-se atenção ao item "Quando uma ideia não é considerada importante para a minha empresa, ela é compartilhada com os atores da cadeia de valor (Fornecedores, Clientes, Concorrentes e Colaboradores) para que possa ser utilizada e desenvolvida em outro local (CAV4)". Ter uma tendência não significativa demonstra que na relação entre as empresas e a cadeia de valor, a inovação aberta para entrega fornecimento de recursos não é tão utilizada como demonstrado nos resultados de fornecimento de tecnologias. Esse resultado também foi encontrado nos estudos de Rodrigues, Maccari e Campanario (2010) e Desiderio e Popadiuk (2015).

Para dar certo, as EBTs precisam: ouvir os envolvidos e manter relação com parceiros para aquisição de novos conhecimentos; saber unir esses novos conhecimentos aos recursos da empresa; e saber difundir essas novas ideias, que serão formadas com as ideias externas e as ideias da própria empresa. Por isso, a importância da cadeia de valor nesse processo.

\subsection{Análises do modelo estrutural}

No modelo estrutural desse estudo avaliou-se a influência entre os constructos Perfil Inovador, Redes de Conhecimento, Estabelecimento de Parcerias, desenvolvimento de Produtos por Licenciamento e Patentes, Spin In e Spin off, Cadeia de Valor e Criação de Valor. Ressalta-se que nenhuma variável foi descartada após as análises realizadas. $O$ resultado aponta que houve influência significativa do Perfil Inovador e Redes de Conhecimento sobre os constructos que compõem a Inovação Aberta, assim como esses constructos apresentaram uma influência positiva e significativa sobre a Criação de valor, conforme Tabela 1 e Figura 2.

As Redes de Conhecimento e o Perfil de Inovação são capazes de compor em maior grau a Cadeia de Valor e em menor grau o Corporate Venturing. Isso indica que as empresas pesquisadas possuem uma relação de rede e inovação quando se mantêm parcerias com os atores de todo o processo de produção e venda. Da mesma forma, o item Corporate Venturing apresentou em menor grau a influência sobre a Criação de Valor. Lindegaard (2010) e Kim e Park (2008) afirmam que na inovação aberta é necessário o reconhecimento de que a inteligência e as melhores ideias podem não fazer parte da organização ou não originarem do P\&D. Por isso, o modelo de inovação precisa estar alinhado às capacidades e conhecimentos externos. 
Tabela 1- Modelo Estrutural e Coeficientes de Medição

\begin{tabular}{|c|c|c|c|c|c|c|}
\hline Endógena & Exógena & $\boldsymbol{\beta}$ & $\begin{array}{l}\text { E.P. } \\
(\beta)\end{array}$ & I.C. - 95\% & Valor-p & $\mathbf{R}^{\mathbf{2}}$ \\
\hline \multirow{2}{*}{$\begin{array}{l}\text { Estabelecimento de } \\
\text { Parcerias }\end{array}$} & Redes de Conhecimento & 0,49 & 0,05 & {$[0,38 ; 0,59]$} & 0,000 & \multirow{2}{*}{$51,10 \%$} \\
\hline & Inovação & 0,28 & 0,05 & {$[0,18 ; 0,40]$} & 0,000 & \\
\hline \multirow{2}{*}{$\begin{array}{l}\text { Desenvolvimento de } \\
\text { Produtos }\end{array}$} & Redes de Conhecimento & 0,35 & 0,06 & {$[0,23 ; 0,46]$} & 0,000 & \multirow{2}{*}{$41,00 \%$} \\
\hline & Inovação & 0,35 & 0,06 & {$[0,24 ; 0,48]$} & 0,000 & \\
\hline \multirow{2}{*}{ Spin offe Spin in } & Redes de Conhecimento & 0,24 & 0,05 & {$[0,13 ; 0,35]$} & 0,000 & \multirow{2}{*}{$50,30 \%$} \\
\hline & Inovação & 0,53 & 0,05 & {$[0,43 ; 0,62]$} & 0,000 & \\
\hline \multirow{2}{*}{ Corporate Venturing } & Redes de Conhecimento & 0,08 & 0,06 & {$[-0,04 ; 0,20]$} & 0,170 & \multirow{2}{*}{$40,80 \%$} \\
\hline & Inovação & 0,58 & 0,06 & {$[0,47 ; 0,70]$} & 0,000 & \\
\hline \multirow{2}{*}{ Cadeia de Valor } & Redes de Conhecimento & 0,26 & 0,04 & {$[0,15 ; 0,36]$} & 0,000 & \multirow{2}{*}{$64,30 \%$} \\
\hline & Inovação & 0,60 & 0,04 & {$[0,51 ; 0,70]$} & 0,000 & \\
\hline \multirow{5}{*}{ CV } & $\begin{array}{l}\text { Estabelecimento de } \\
\text { Parcerias }\end{array}$ & 0,25 & 0,03 & {$[0,19 ; 0,31]$} & 0,000 & \multirow{5}{*}{$88,90 \%$} \\
\hline & $\begin{array}{l}\text { Desenvolvimento de } \\
\text { Produtos }\end{array}$ & 0,24 & 0,03 & {$[0,18 ; 0,30]$} & 0,000 & \\
\hline & Spin offe Spin in & 0,27 & 0,03 & {$[0,21 ; 0,33]$} & 0,000 & \\
\hline & Corporate Venturing & 0,15 & 0,02 & {$[0,09 ; 0,22]$} & 0,000 & \\
\hline & Cadeia de Valor & 0,21 & 0,03 & {$[0,15 ; 0,27]$} & 0,000 & \\
\hline
\end{tabular}

Fonte: Dados da pesquisa (2017).

Figura 2- Modelo Estrutural

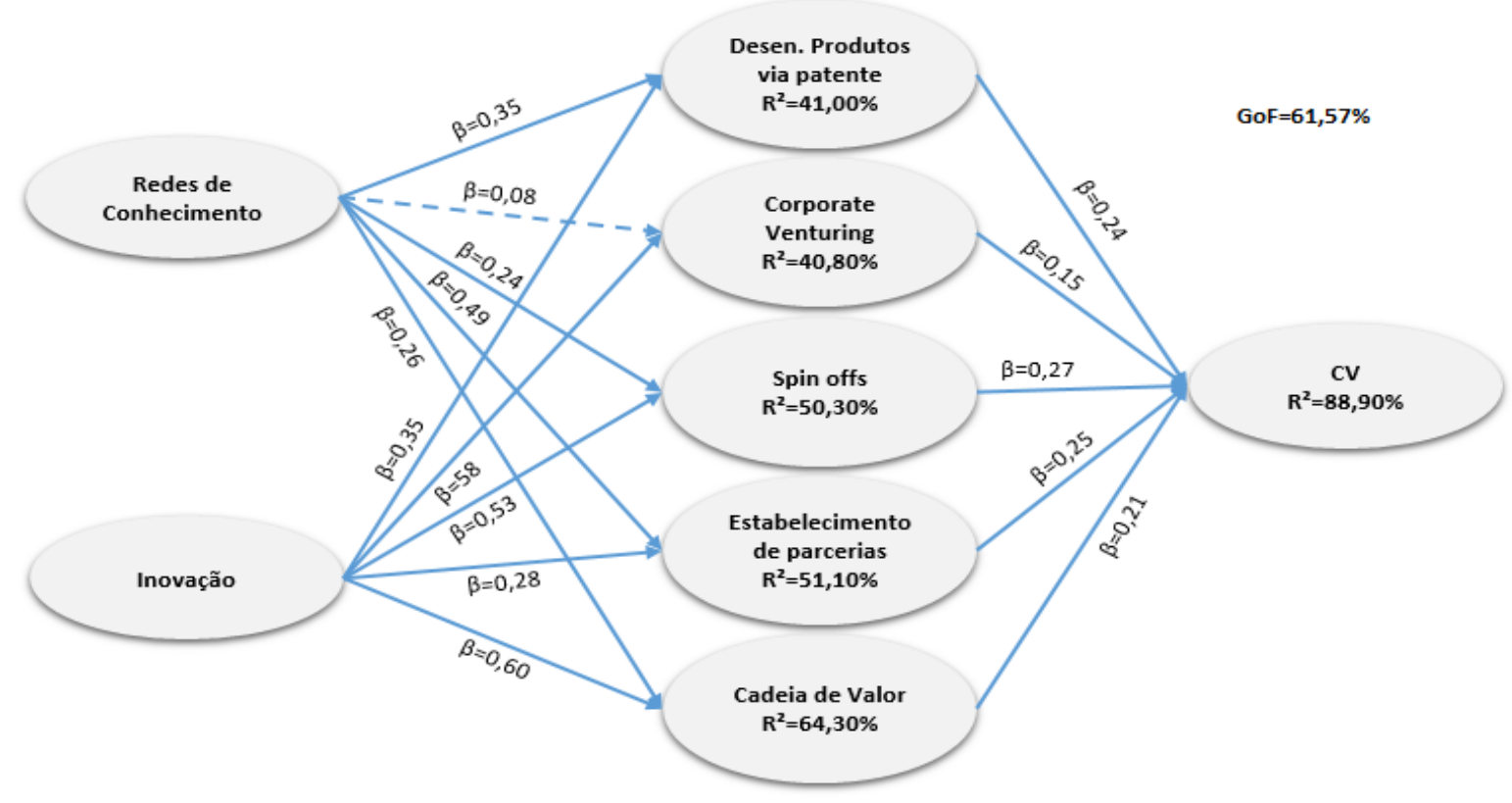

Fonte: Dados da pesquisa (2017).

As interações com os sistemas científicos abrem campo para a aplicação de ideias desenvolvidas somente dentro desses sistemas, devido à ausência de recursos humanos, financeiros e de equipamentos nas organizações. A junção de modelos de negócios com outras organizações é ser capaz de acelerar as etapas de produção e aumentar a possibilidade de inovação. Por isso, é importante romper barreiras internas de investimento. Compartilhar recursos permite que novas formas de integração e aplicação desses à novos produtos, sejam conhecidas e melhoradas continuamente (CHESBROUGH, 2006; SENER; HOBIKIGLU, 2013). As empresas, mesmo com poucos recursos, desenvolvem com investimentos externos. 
Ressalta-se que o coeficiente representado por $\beta$, quantifica a força e o sentido das relações entre os constructos Estabelecimento de Parcerias (0,35), Desenvolvimento de Produtos por Licenciamento e Patentes $(0,24)$, Spin in e Spin off $(0,27)$, Corporate Venturing $(0,27)$ e Cadeia de Valor $(0,21)$ sobre a Criação de Valor. Os intervalos de confiança via bootstrap estão de acordo com os resultados encontrados via valor-p, evidenciando maior validade dos resultados apresentados.

Além disso, os constructos que compõem a Inovação Aberta explicam $88,90 \%$ da Criação de Valor. Além das relações entre variáveis exógenas e variáveis endógenas, verificou-se a existência de efeitos indiretos e significativos das relações entre Redes de Conhecimento e Criação de Valor $(0,34$ [0,25; 0,42])

\section{CONSIDERAÇõES FINAIS}

A inovação é considerada uma ferramenta capaz de realizar modificações nas estruturas organizacionais, proporcionar benefícios socioeconômicos e apoiar o desenvolvimento das empresas. Porém, a realidade que se tem ainda é a disparidade de dominação do mercado, em que algumas organizações apresentam vantagens competitivas e possibilidades de crescimento maiores que outras. Isso ocorre devido à falta de recursos materiais, financeiros, tecnológicos e intelectuais, que impossibilitam as organizações na realização e manutenção de práticas inovadoras.

A inovação aberta cria a possibilidade de democratização da inovação e permite que organizações de qualquer tamanho possam concorrer umas com as outras. Essa democratização surge da formação de redes de conhecimento que possibilita o compartilhamento de informação, recursos e conhecimentos. Para que a inovação aberta seja aplicada, as organizações necessitam manter processos eficientes e apresentarem modelos de negócios que criem estratégias e influenciem uma cultura organizacional voltada à inovação.

O papel da liderança é fundamental. Observou-se que algumas práticas iniciais da inovação aberta já estão presentes nas EBTs Brasileiras. Foram identificadas práticas do estabelecimento de parceria, spin ine spin off, desenvolvimento de produtos por licenciamento e patentes e cadeia de valor. O fator corporate venturing não demonstrou resultados suficientes que indiquem sua utilização.

O resultado apontou também que todos os fatores de inovação aberta propostos no modelo (estabelecimento de parcerias, desenvolvimento de produtos por licenciamento e patentes, spin in e spin off, corporate venturing e cadeia de valor) se correlacionam de maneira significativa e positiva na criação de valor das EBTs. O estabelecimento de parcerias, o desenvolvimento de produtos, o spin in e spin off, o corporate venturing e a cadeia de valor foram capazes de explicar $88,90 \%$ da criação de valor.

De modo geral, a pesquisa identificou os fatores propostos pela inovação aberta para criação de valor e contribuiu, por meio da mensuração do resultado, para a identificação de que as práticas de inovação aberta ainda são incipientes nas Empresas de Base Tecnológica. Como limitações desse estudo, relata-se que não há mensuração da quantidade exata de empresas participantes do estudo, haja vista que a técnica de coleta de dados escolhida foi a Snowball.

Após alcançar os resultados e identificar as limitações do estudo, sugere-se que novas pesquisas sejam realizadas agregando análises qualitativas que identifiquem características que a quantitativa não ofereça. Outra sugestão de pesquisa futura é a validação do modelo proposto para identificação da inovação aberta em outros segmentos organizacionais, haja vista que os resultados encontrados são específicos às EBTs.

\section{REFERÊNCIAS}

ADES, C. et al. Implementing open innovation: the case of Natura, IBM and Siemens. Journal of Technology Management \& Innovation, v, 8, p. 12-25. 2013. Número especial.

ARAÚJO, Roberto Pinto; MOTTIN, Antonio Paulo; REZENDE, José Francisco de Carvalho. Gestão do conhecimento e do capital intelectual: mapeamento da produção acadêmica brasileira de 1997 a 2011 nos encontros da Anpad. Organizações \& Sociedade, v. 20, n. 65, 2013. 
BALDIN, N., MUNHOZ, E. M. Bagatin. Snowball (Bola de Neve): uma técnica metodológica para pesquisa em educação ambiental comunitária. In: CONGRESSO INTERNACIONAL DE EDUCAÇÃO, 10., 2011, Curitiba. Anais [...]. Curitiba: UFPR, 2011. p. 229-341.

BOCKEN, N. M. P. Sustainable venture capital: catalyst for sustainable start-up success? Journal of Cleaner Production, v, 108, p. 647-658. 2015

BONNER, Bryan L.; BAUMANN, Michael R. Leveraging member expertise to improve knowledge transfer and demonstrability in groups. Journal of Personality and Social Psychology, v. 102, n. 2, p. 337-350, 2012.

BRITO, Renata Peregrino de; BRITO, Luiz Artur Ledur. Competitive advantage and performance: a value creation approach. Revista de Administração Contemporânea, Rio de Janeiro, v. 16, n. 3, p. 360-380, maio/jun. 2012.

CELADON, Kleber Luís. Knowledge Integration and Open Innovation in the Brazilian Cosmetics Industry. Journal Technology Management e Innovation, v. 9, n. 3, p. 34-50, 2014.

CHANDRA, A.; CHAO, C. Growth and evolution of high-technology business incubation in China. Human Systems Management, v. 30, p. 55-69, 2011.

CHEN, Yufen. A study on the modes of open innovation matched with firms' internal capabilities. In: Proceedings of PICMET'14 Conference: PORTLAND INTERNATIONAL CENTER FOR MANAGEMENT OF ENGINEERING AND TECHNOLOGY; INFRASTRUCTURE AND SERVICE INTEGRATION, 2014, Portland. Proceedings [...]. Portland: IEEE, 2014. p. 921-931.

CHEN, C.; HUANG, Y. Creative workforce density, organizational slack, and innovation performance. Journal of Business Research, Taiwan, v. 63, p. 411-417, 2010.

CHEN, Lin et al. Negative samples reduction in cross-company software defects prediction. Information and Software Technology, Macau, v. 62, p. 67-77, 2015.

CHESBROUGH, H. W. The era of open innovation. MIT Sloan Management Review, Boston, v. 44, n. 3, p. 3541, 2003.

CHESBROUGH, H. W. Open Innovation: the new imperative for creating and profiting from technology. Boston: Harvard Business School Press, 2006.

COSTA, Silvia Generali da. Comportamento organizacional-cultura e casos brasileiros. Rio de Janeiro: LTC, 2014.

DESIDERIO, P. H. M.; POPADIUK, S. Redes de inovação aberta e compartilhamento do conhecimento: aplicações em pequenas empresas. Revista de Administração e Inovação, p. 12, n. 2, p. 110-129, 2015.

DIAS, Reinaldo. Cultura organizacional: construção, consolidação e mudanças. São Paulo: Atlas, 2013.

FLORES, R. L. et al. Open computer aided innovation to promote innovation in process engineering. Chemical engineering research and design, Toulouse, n. 103, p. 90-107, 2015.

GUAN, Jiancheng; LIU, Na. Exploitative and exploratory innovations in knowledge network and collaboration network: A patent analysis in the technological field ofnano-energy. Research Policy, v. 45, p. 97-112, 2016.

HEREDERO, Carmen de Pablos. SANTOS, Ignacio Soret; EGUILAZ, Máxima Juliana López-Eguilaz. A model to measure results in open innovation practices. Journal Technology Management Innovation, v. 8, p. 84-92, 2013. Número especial.

HERRERA, Maria Elena Baltazar. Creating competitive advantage by institutionalizing corporate social innovation. Journal of Business Research, n. 68, p. 1468-1474, 2015.

JOHANNSON, M. et al. Space and open innovation: potential, limitations and conditions of success. CtaAstronautica, v. 115, p. 173-184, 2015. 
KIM, Junyoung; PARK, Yongtae. The usefulness of patent stage and sectoral pattern in open innovation licensing. Journal Technology Management Innovation, v. 3, n. 4, 2008.

LINDEGAARD, Stefan. The open innovation revolution: essentials, roadblocks and leadership skills. Nova Jersey, EUA: Wiley, 2010.

LIU, F.; ZHENG, G. Open Innovation in Chinese High-tech Enterprises: An Empirical Research Based on Zhejiang Province. Shejiang: School of Management, 2011.

MASSAINI, S.; OLIVA, F. L. Redes de Inovação: a contribuição de parcerias para o desempenho inovador de empresas da indústria elétrica eletrônica brasileira. Brazilian Business Review, Vitória, v. 12, n. 13, p. 17-44, 2015.

MOREIRA, B. et al. As oportunidades e os desafios do open innovation no Brasil. Instituto Inovação. 2008. Disponível em: http://inei.org.br/inovateca/artigos-sobre-empreendedorismo-einovacao/as_oportunidades_e_desafios_do_open_innovation_no_brasil.pdf/at_download/file. Acesso em: 19 jun. 2019.

NONAKA, Ikujiro; TAKEUCHI, Hirotaka. Gestão do conhecimento. Porto Alegre: Bookman, 2008.

$\mathrm{OH}$ TEAK, Eun. Value creation in regional innovation systems: The case of Taiwan's ma-chine tool enterprises. Technological Forecasting \& Social Change, v. 100, p. 118-129, Oct. 2015.

OLIVEIRA, S. R. M.; ALVES, J. L. Influência das práticas de open innovation na prospecção de conhecimentos para a criação de valor em ambientes de alta complexidade sob condições de incerteza e imprevisibilidade. Revista de Administração e Inovação, São Paulo, v.11, n. 1, p. 295-318.2013.

ORGANIZAÇÃO PARA COOPERAÇÃO E DESENVOLVIMENTO ECONÔMICO - OCDE. Manual de Oslo: Diretrizes para coleta e interpretação de dados sobre inovação. São Paulo: Finep, 2005.

PINHO, M. et al. Empresas de base tecnológica. São Carlos: Universidade Federal de São Carlos, 2005.

PITASSI, Cláudio. A virtualidade nas estratégias de inovação aberta: proposta de articulação conceitual. RAPRevista de Administração Pública, v. 46, n. 2, p. 619- 641. 2012.

ROMAM, Darlan José et al. Fatores de competitividade organizacional. BBR- Brazilian Business Review, Vitória, v. 9, n. 1, p. 27-46, jan./mar. 2012.

RODRIGUES, Leonel Zezar; MACCARI, Emerson Antonio; CAMPANARIO, Milton de Abreu. Expandingthe open innovation concept: the case of TOTVS s/a. JISTEM - Revista de Gestão da Tecnologia e Sistemas de Informação, v. 7, n. 3, p. 737-754, 2010.

SAEBI, T.; FOSS, N. J. Business models for open innovation: Matching heterogeneous open innovation strategies with business model dimensions. European Management Journal, v. 3, p. 201-213, 2015.

SANTOS, D. T. dos S.; PINHO, M. Análise do crescimento das empresas de base tecnológica no Brasil. Produção, v. 20, n. 2, p. 214-223, 2010.

SCHMID, Julia C.; KNIERIM, Andrea; KNUTH, Ulrike. Policy-induced innovations networks on climate change adaptation: an ex-post analysis of collaboration success and its influencing factors. Environmental Science \& Policy, v. 56, p. 67-79, Feb. 2016.

SENER, S.; HOBIKOGLU, E. H. Structural effect of enterprises open-closed innovation models tendencies in product output process: a study on the enterprises located in the IMES industrial estate Turkey example. Procedia - Social and Behavioral Sciences, Istanbul, v. 99, p. 986-996, 2013.

SIE, R. L.L. et al. Factors that influence cooperation in networks for innovation and learning. Computers in Human Behavior, n. 37, p. 377-384, 2014. 
SIRMON, David G.; HITT, Michael A.; IRELAND, Duane. O gerenciamento de recursos em-presariais em ambientes dinâmicos visando a geração de valor: olhando dentro da caixa preta. In: LACERDA, Daniel Pacheco et al. (org.). Estratégias baseadas em recursos: 15 artigos clássicos para sustentar vantagens competitivas. Porto Alegre: Bookman, 2014. p. 299-331.

STAL, E., NOHARA, J. J.; CHAGAS JUNIOR, M. de F. Os conceitos de inovação aberta e o desempenho de empresas brasileiras inovadoras. Revista de Administração e Inovação, São Paulo, v. 11, n. 2, p. 295-320, 2014.

VECCHIATO, Riccardo. Creating value through foresight: First mover advantages and strategic agility.

Technological Forecasting \& Social Change, v. 101, p. 25-36, 2015.

VELIC, Amila; MARJANOVIC, Olivera. Integrating open innovation and business process innovation: Insights from a large-scale study on a transition economy. Information \& Management, v. 53, n. 3, p. 398-408, 2016.

VERGARA, S. C. Métodos de pesquisa em administração. 6. ed. São Paulo: Atlas, 2015.

VINZI et al. Handbook of Partial Least Squares. Switzerland: Springer, 2010.

ZIVIANI, F. et al. Gestão da inovação no setor elétrico brasileiro: um estudo das fontes e obstáculos à inovação. In:SANTOS, J. A. C. (org.). TMS Conference Series. Faro, Portugal: Universidade do Algarve, 2016. p. $209-219$. 